\title{
Assessing Country-Of-Origin Effects: The Impact Of An International Event
}

Yoon C. Cho, (E-mail: ycho@hpu.edu), Hawaii Pacific University

Joseph Ha, (E-mail: jha@hpu.edu), Hawaii Pacific University

\begin{abstract}
This study is to investigate how consumers' attitudes toward brands/products manufactured by a country are affected by an international event. Authors explored that consumers' attitudes toward brand "made in __" are affected by various constructs, such as prior beliefs about the products' attributes, the country's image along with the brand name, and attitudes toward the advertising during an international event.
\end{abstract}

\section{INTRODUCTION}

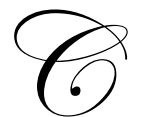

ountry of origin effects has been frequently investigated since the 1960s. However, most recently, topics on country of origin have had less attention paid to them by researchers, even though consumers' attitudes toward "made in" or country of origin have consistently affected their purchase decision over the past years. Country of origin has impacted consumers' product or brand evaluations as an information cue, which significantly affects consumers' assessments through its ability to bias such evaluations (Bilkey and Nes 1982; Han 1989). The "stereotype" of the country (Samiee 1994) constructed by such assessments is affected by the consumers' positive or negative attitudes toward products from that country. Brand names from a country that's been favorably stereotyped have sold well. For instance, the Mercedes, automobile brand is closely related to the consumers' image of Germany as a technologically advanced country. Sometimes, brand names have been successfully established without an association with the country of origin. An example is Nokia, Swedish brand that consumers like without even knowing its country of origin. Samsung, as another example, is known as a technologically advanced brand, yet its country of origin, the Republic of Korea does not have strong stereotype as a technologically advanced society like Germany. These observations indicate the country of origin is only one cue to affecting consumers' product evaluations and purchase decisions.

Previous research has also addressed the effects of advertising on consumer's beliefs. A study by Mitchell and Olson (1981) found that brand attitudes are not solely a function of the attribute beliefs that are formed about the brand, but may also be influenced by consumers' general liking of the ad itself or the visual stimulus presented in the advertisement. While advertising's effects on attitudes toward the country of origin and brand "made in" have been duly noted, the effects of advertising during an international event on attitudes toward the country of origin rarely have been studied by researchers. Therefore, the purpose of this study is to measure how advertising exposure during an international event can change overall consumers' attitudes toward brands with a "made in __," particularly for brands made in the host country. Second, this study measures Japanese consumers attitudes toward brands made in the Republic of Korea. While the two countries have had long-term political, geographical, economic, and cultural relation, studies about Japanese (or Korean) attitudes toward brands made in Korea (or Japan) have not been frequently researched. Therefore, this is another motivation of this study.

Based on the issues above, this study considered three variables that affect overall attitudes toward the brands with the "made in _ " after an international event. Those variables include consumers' attitudes toward advertising, the country's image along with the brand, and prior beliefs. Of particular concern, this study explores how Japanese consumers' attitudes changed during the international event toward brands, made in the Republic of Korea (ROK). Previous studies have studied the effects of "country stereotypes (Samiee 1994; Lots and Hu 2001)," but studies on "country stereotypes" between two ethnic groups such as Korean and Japanese have not frequently researched. This 
study examines how Japanese consumers, whose culture mirrors Hofstede's (1991) dimensions of cultural variability collectivism, Confucian dynamism, and power distance - perceive differently Korea and its product brands as a consequence of the international event.

Marketing campaigns during events, such as the Olympics, soccer, or the Super Bowl have proven to be effective in enhancing brand awareness. Most recently, monster.com received strong brand recognition through its campaign during the Super Bowl (Rayport and Jaworski 2001). Advertising exposure during an international event greatly benefits a product and a brand (Anonymous 2002). Previous studies have been often investigated the relationship between advertising effects and attitudes toward brands. Based on Gardner (1983), advertising affects attitudes toward the country of origin and brands through attributes recalled and criteria used for brand evaluation. Therefore, another issue of this study is to measure how advertising during an international event affects consumers' attitudes toward specific brands.

This study also explores image variables, associated with the country of origin. Various researchers have questioned the country of origin effects as an image variable. A study by Erickson, Johansson, and Chao (1984) considers the influence of image variables on the formation of beliefs and attitudes. Of particular concern, this study measures Japanese consumers' attitudes toward an automobile manufacturer, Hyundai, and its country of origin, the ROK. The World Cup 2002, is used as an intermediary tool to investigate whether the event positively or negatively influenced brand awareness and Korea's image in Japan. The framework of the Fishbein Model is applied in order to measure consumers' attitudes toward Hyundai. Attributes such as price, quality of the product, design, performance, and brand image are considered as weights. Consumers' evaluative aspects of beliefs toward each attribute have been used in order to measure the changes of attitude toward Hyundai after World Cup 2002. Attribution theory was also employed as a useful theoretical foundation to explain the effects of a special event, as the theory is concerned with the processes by which people give meaning to the events around them (Runyon and Stewart 1987).

\section{CONCEPTUAL FRAMEWORK}

\section{Conceptual Model}

The most frequently used model to explain country of origin effects is the Fishbein model. Much of the marketing research based on the Fishbein's attitude model (i.e., $\left.A_{O}=\sum_{i=1}^{n} b_{i} e_{i}\right)^{1}$ has focused on demonstrating statistically significant correlations between a "direct" measure of brand attitude (e.g., $\left.A_{O}\right)$ and the cognitive structure index of attitude $\left(\sum_{i=1}^{n} b_{i} e_{i}\right)$ based on product attribute beliefs (Mitchell and Olson 1981; Wilkie and Pessemier 1973). Previous study by Erickson, Johanson, and Chao (1984) investigated the effects of image variables on beliefs and attitudes in the multi-attribute model framework. A study by Mitchell and Olson (1981) also applied attitude theory to explain whether product attribute beliefs are only the mediator of advertising effects on brand attitude. Mitchell and Olson (1981) examined the validity of the basic theoretical proposition of the Fishbein attitude theory in a marketing research context. Various researchers have developed the model by adding other variables, such as image variable (Erickson, Johansson, and Chao 1984) and advertising effects (Mitchell and Olson 1981). Attitudes toward the products' country of origin used as a variable to explain consumers' attitudes toward the brands in this

\footnotetext{
${ }^{1}$ Where:

$b_{i} \quad=$ The strength of the association about the level of product attribute $\mathrm{i}$.

$e_{i} \quad=$ The evaluation of the $\mathrm{i}^{\text {th }}$ salient concept,

$A_{O} \quad=$ The overall evaluation of, or attitude toward, concept, and

$\mathrm{n} \quad \quad=$ The number of salient beliefs.
} 
study, are considered as the subjective norm, which is determined by beliefs about the normative proscriptions of specific others and the individuals' motivation to comply with those specific others (Ajzen and Fishbein 1980).

\section{Model Development}

This study has theoretical implications. First, this study measures how international event affect attitude changes toward brands and a country's image. This study modified the effects of advertising on attitude changes from the study by Mitchell and Olson (1981) with special concentration on advertising's effect on beliefs and attitudes after the international event. Second, this study proposed that attitudes toward a brand's country of origin after advertising can be measured as summary effects of prior beliefs about products attributes of the brand before exposed by advertising, attitudes toward the advertising, and country image along with product attributes. Country of effects, as an image variable has been considered in this analysis to measure consumers' towards the specific product, originated from a certain country in the model of the effects of advertising exposure in an international event to the brand and its country of origin. Previous studies consider country of origin as a halo (country image -> beliefs $->$ brand attitude: Erickson, Johansson, \& Chao 1984; Johansson, Douglas, and Nonaka 1985) or a summary construct (beliefs -> country image $->$ brand attitude: Han 1989). In this study, attitudes toward the brand, originated from a country is summary measure or beliefs about product attributes and country image (Figure 1). Therefore, this study concerns whether beliefs about product attributes and country image along with product attributes are together affect attitudes toward the brand, originated from a country, but does not measure the cause and effects between beliefs about product attributes and country image along with product attributes.

Figure 1:

Attitudes Changes Toward the Brand along with Country or Origin:

The Impact of an International Event (Adapted from Mitchell and Olson 1981; Erickson, Johansson, \& Chao 1984)

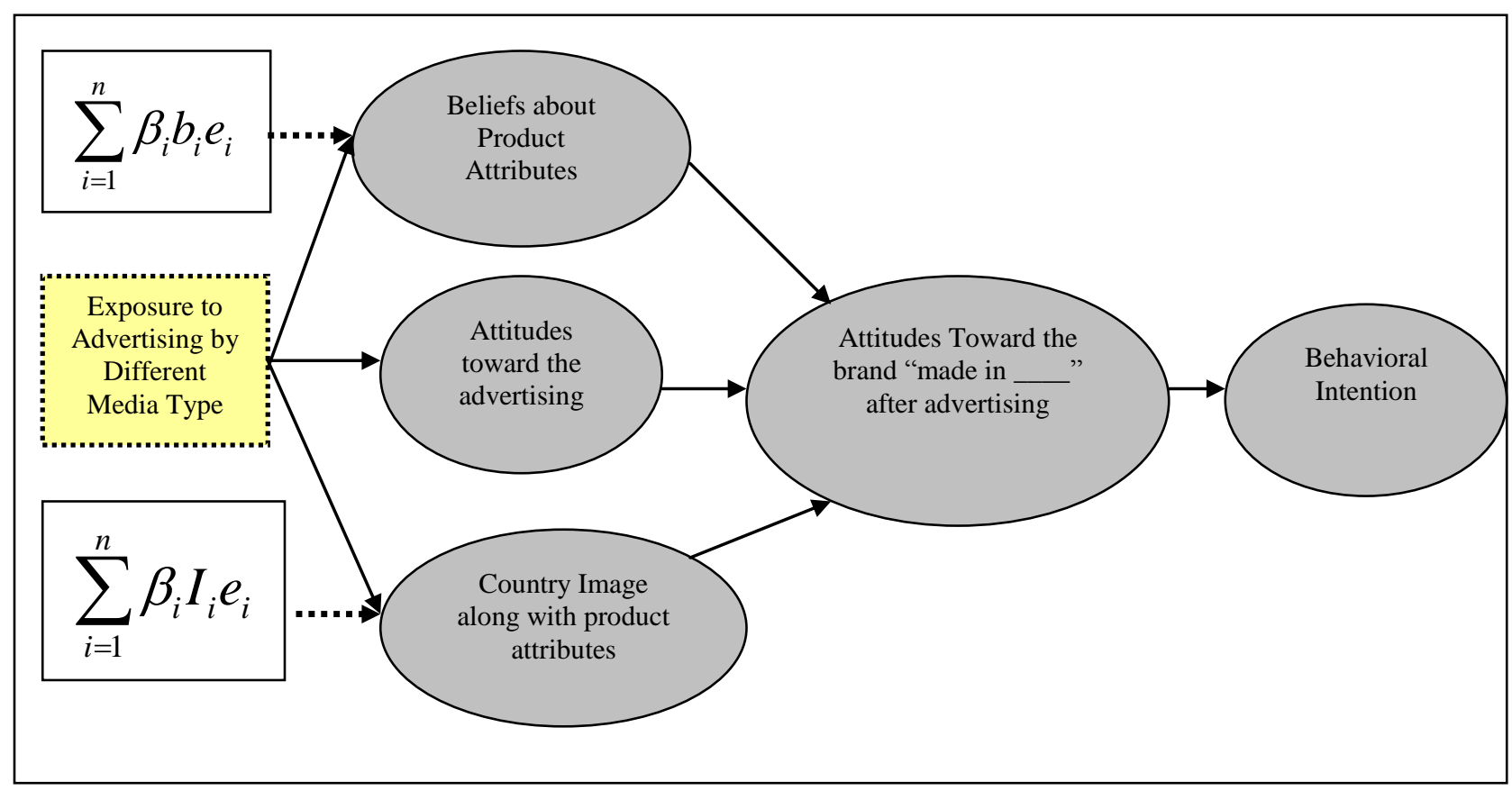

The present study extended the Fishbein model to estimate variable relationships, such as the effects of advertising in an international event, country image along with product attributes, beliefs about product attributes, and the attitudes toward brands labeled "made in." Attitudes toward the product attributes are obtained in this study by measuring the total products of product belief strength and attribute evaluation for each product attribute (i.e., 
$\left.\sum_{i=1}^{n} \beta_{i} b_{i} e_{i}\right)$. Attitudes toward the product from a specific country are measured by considering the total multiplications of the image strength for each product's attributes, originated from a specific country, and the attribute evaluation for each product's attribute. The modified Fishbein model proposed in this study is extended from two previous studies, Mitchell and Olson (1981) and Erickson, Johanson, and Chao (1984). The extended model, used in this study is as follows:

$$
A_{O}=\alpha+\sum_{i=1}^{n} \beta_{i} b_{i} e_{i}+\beta_{k} D_{k}+\beta_{A D} A_{A D}+\sum_{j=1}^{n} \beta_{j} I_{j} e_{j}+\varepsilon
$$

where:

$A_{O} \quad=$ The attitudes toward the brand after international event,

$b_{i} \quad=$ Belief strength for the $i^{\text {th }}$ attribute,

$e_{i} \quad=$ Attribute evaluation for the $i^{\text {th }}$ attribute,

$A_{A D} \quad=$ The strength of recalls on a brand's advertisement

$D_{k} \quad=1$ if $\mathrm{k}$ has not been exposed by advertising,

$I_{j} \quad=$ Image strength for the $j^{\text {th }}$ attribute on the product, made in a specific country.

$n \quad=$ The number of salient beliefs.

$\beta_{i}, \beta_{k}, \beta_{A D}, \& \beta_{j}=$ Coefficients of variables.

\section{The Effects Of Product Attribute Beliefs}

A previous study by Mitchell and Olson (1981), found that product attribute beliefs had a major mediating effect on brand attitudes, whereas attitudes substantially mediated behavioral intentions.

Among the three kinds of beliefs (descriptive, inferential, and informational: Fishbein and Ajzen 1975), informational beliefs are described as the one influenced by outside sources of information (Erickson, Johanson, and Chao 1984; Holbrook 1978; Mitchell and Olson 1981; Toy 1982). A study by Mitchell and Olson (1981) extended Fishbein's belief and attitude relationship and found that beliefs about product attributes are the only mediator of brand attitude. In the same study, Mitchell and Olson (1981) posited that the product attribute belief index, $\sum_{i=1}^{n} b_{i} e_{i}$, was not the sole mediator of attitude information, but also a measure of attitude toward the advertisement, partially mediating advertising's effects on brand attitudes. This study adopts the previous study's result by Mitchell and Olson (1981) and hypothesizes how consumers' attitudes toward brands as summary measures of attributes for a product,

$\sum_{i=1}^{n} \beta_{i} b_{i} e_{i}$, are affected by advertising exposure during an international event. Specifically, the study examines how advertising exposure, sponsored by the hosting company of the event, changes consumers' attitudes toward brands and advertised products. Specifically, this study examines the effects of overall Japanese consumers' attitudes toward the automobile brand $\left(A_{O}\right)$, Hyundai, advertised during an international event, co-hosted by its neighbor country, the Republic of Korea. This study measures how consumers' perception of the importance of the product attributes affects beliefs about brands labeled "made in" after they have been exposed by advertising during an international event. This study also hypothesizes that the beliefs about the brands labeled "made in" affect changes in attitudes about brands originating from a particular country. 
Hypothesis 1: The beliefs about a product's attributes will positively affect attitudes toward brands labeled "made in" after an international event.

\section{The Country Of Origin Effects}

Country of origin has been considered a product cue for a product's source country - also called the "Made In " (Bilkey and Nes 1982). Previous studies have frequently researched the influence of country of origin on consumers' attitudes toward brands, purchase decision, and evaluation of the product (Bilkey and Nes 1982; Anderson and Cunningham 1972; Kaynak, Kuchkemiroglu, and Hyder 2000). Studies, such as Erickson, Johanson, and Chao (1984) found that country of origin is an image variable, which may have inferential effects on product beliefs and attitude indirectly. Papadopoulos (1993) posited sequential steps in the determination of consumers' perceptions of a product's country of origin. According to Papadopoulos (1993), consumers first develop an overall image of a foreign country, formulating that image, along with constructs concerning a variety of products from the same nation with which the consumer is familiar. Papadopoulos (1993) also stated that country of origin stereotypes prompt a variety of images about products' characteristics such as product quality and price that have been established through repeated past experiences. In Han (1989), country image serves as a halo in product evaluation and it has been viewed as a summary contract. Han (1989) posited that consumers might abstract information about a country's products because brands from the same country have very similar product attributes. Leclerc and Schmitt (1994) found that foreign branding could be an effective means of influencing consumers' perceptions and attitudes by testing the stereotype of France and French culture.

Figure 2:

Various Country Images in Japan: Impact of an International Event on Co-Hosted Country's Image

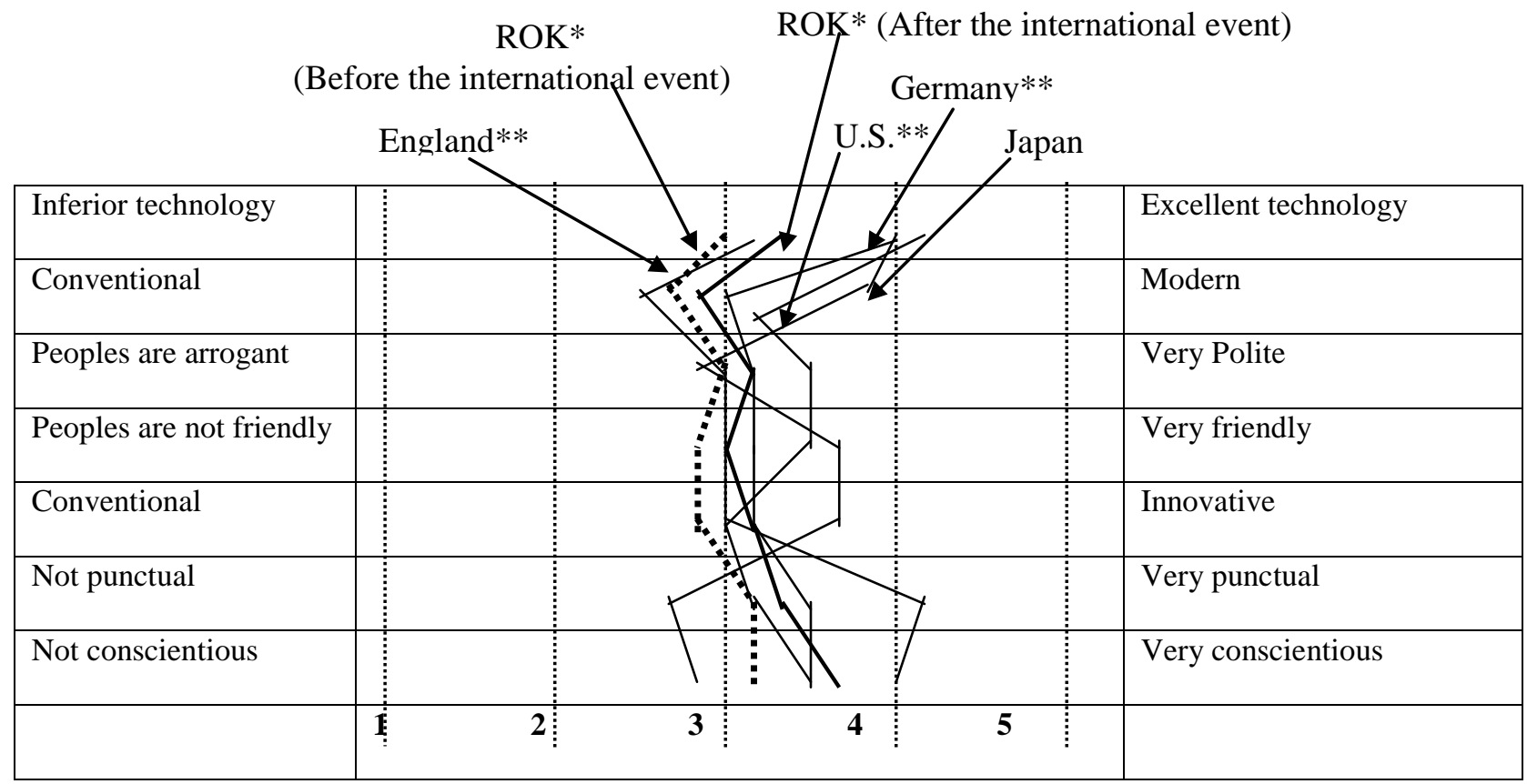

* ROK: Republic of Korea

** Germany, England, and U.S. are not major concern for this study, while we measured for comparison.

This study measures what images Japanese consumers have of foreign countries (i.e., U.S., Germany, England, and the Republic of Korea) and their products' attributes and how images of country, Republic of Korea have changed after advertising during the international event. Semantic differential scales were used in this analysis. 
This study selected countries such as U.S., Germany, England, Japan and Republic of Korea to compare different images on different attributes. Countries selected because automobiles made in those countries have obtained market share in Japanese automobile market for several years. For a particular concern, this study measured the image of the ROK before and after the World Cup 2002. Figure 2 shows that "country image" has been positively improved in Japan after the World Cup 2002. As shown in figure 2, mean values for the ROK are relatively low compared to other developed countries, such as England, Germany, and U.S. before the international event (see dashed line with the bold). However, mean values for the image variables of ROK after the international event are increased (see the solid line with the bold). The results imply that the international event gives significantly improves the host country's image.

This study also measures how the Japanese perceive the image of the automobiles made in foreign countries (i.e., U.S., Germany, England, and South Korea), by asking about product attributes and service aspects. This study also measures the image of the automobiles made in South Korea before and after the World Cup 2002. Similar to the impact on the co-hosted country's image, the image of the product (e.g., automobile) made in the co-host's country also has improved positively (see Figure 3: dashed line with the bold for before international event; the solid line with the bold for after international event). This result also shows that mean values for the ROK have been relatively improved, but overall, the scores for the product attributes and service aspects were much lower for the automobiles made in the ROK than made in other foreign countries.

Figure 3:

Image of the Automobiles made in Various Countries in Japan:

Impact of International Event on Brands Made In Co-Hosted Country

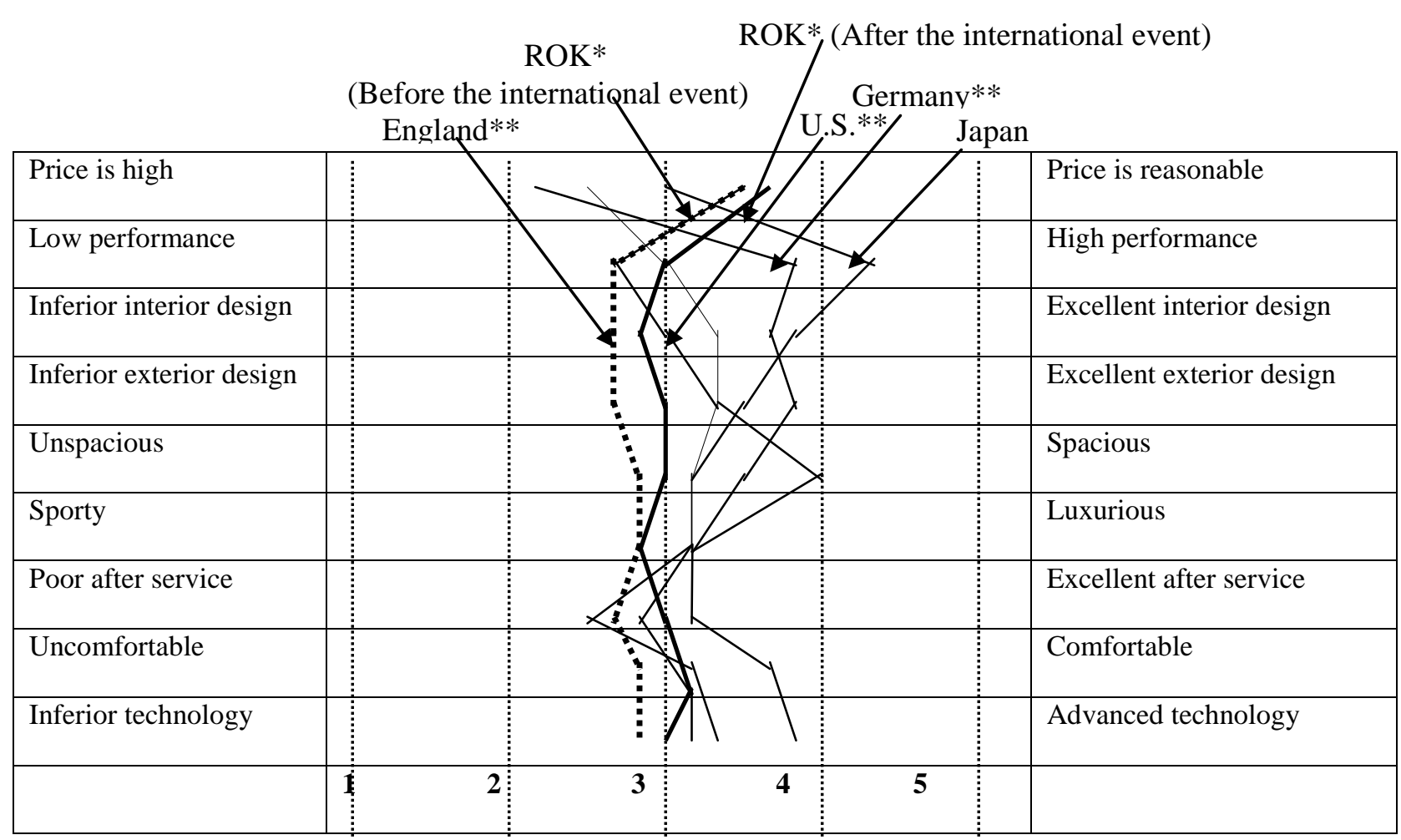

* ROK: Republic of Korea

** Germany, England, and U.S. are not major concern for this study, while we measured for comparison.

While various studies discussed the effect of attitudes toward the product attributes or attitudes toward the image of the products' country of origin on overall attitudes toward brands, the studies hardly measure how 
consumers' overall attitudes toward the brand will be changed when both variables, attitudes toward the product attributes and attitudes toward the image of the products' country of origin are considered. Thus, the present study measures how two predictors together affect consumers' overall attitude toward the brand. This study hypothesizes how consumers' attitudes toward brands, originating from a specific country have been applied to evaluate multiattribute products after the advertising is viewed during the international event. Therefore, country of origin is used as an image variable (Erickson, Johansson, and Chao 1984) in this study to measure the changes of consumers' attitudes toward the brand.

Hypothesis 2: The country image, along with the brand will positively affect consumers' attitudes toward the brand's "made in __ " after an international event.

\section{The Effects Of Advertising Recall}

It is well known that the objective of advertising is to increase brand awareness and to change attitudes toward the brand or product. The effects of advertising have been frequently examined by various researchers. Both recall and recognition have been frequently used to measure the effects of advertising. According to Singh and Rothschild (1983), on a recall test a subject is first given a set of information and is later given some minimal cue and asked to retrieve and reconstruct the original information, whereas in a recognition test the subject is confronted with the original material and asked whether it has been seen or heard before (Singh and Rothschild 1983).

Both recall and recognition have become two important tools to measure the effects of advertising, specifically how advertising messages affect consumers' beliefs and attitudes toward the brand or product (Wright 1978). Studies such as by Gardner's (1983) used recall to measure instead of recognition. Gardner investigated advertising effects on recalling product attributes and criteria used for brand evaluation. However, Haskins (1964) and Krugman (1972) posited that recall may not be the most appropriate measure of learning effectiveness and stressed that recognition may be better in certain situations. In this study, recall is considered as a tool to measure subjects' ability to remember the advertising of a specific brand whether it has been heard during the period of marketing campaign. We explore how subjects recall the advertising, promoted during the marketing campaign and the strength of recall affecting consumers' attitudes toward the brand.

Hypothesis 3: As consumers recall advertising during an international event, consumers' attitudes toward the brand's "made in __" will increase.

Hypothesis 4: As consumers more positively recall the advertising during an international event, consumers' attitudes toward the brand's "made in ___ will increase.

\section{Advertising Effects By Different Medium}

During an international event, sponsors promote their brand via several media. Various studies have explored the effects of different media, such as television, print, or radio. Recently, the effects of advertising online have attracted the attention of academics and businesses. The effects of different media have been implied consideration of how the dimension of a transmission's format, such as the sensory mode used, the number of modalities used concurrently, and the ease of referability (Wright 1974). The effects of different media have been paid attentions to researchers, as the degree of interactivity might affect consumers' recall or recognition of the advertising. The Internet, as a new medium for computer-mediated communication (Hoffman, Novak, and Chatterjee 1995), provides the highest degree of interactivity. While a potential consumer's recall about the sponsor's advertising via the Internet might be high, it might be higher if an individual recalls the sponsor's advertising on TV, because during the game, consumers' involvement usually increases. In this study, the authors examine how advertising and promotion by different media affect consumers' attitudes toward brands. This study examines the effects of advertising that consumers primarily recall enhance their attitudes toward the brand positively. Thus, the impact of the advertising, promoted by different media during an international event, is hypothesized as follows. 
Hypothesis 5: The impact of advertising exposure on attitudes toward brands will differ when exposed by different types of media.

\section{Attitudes Toward Brands And Behavioral Intention}

According to the cognitive structure model, which has its theoretical roots in learning theory, suggested by Toy (1982), the emphasis is on beliefs as the fundamental cognitive element (Fishbein and Ajzen 1975). Fishbein's model of attitude formation implied the effects of persuasive communication on attitudes indirectly via the formation of beliefs

(Message Exposure -> $\sum_{i=1}^{n} b_{i} e_{i}$-> A -> BI (Behavioral Intentions) -> B (Behavior)) (see also Toy 1982). This study measures how attitudes toward brand's "made in ___ affects behavioral intention after exposed by advertising. This study measures how the change in Japanese consumers' attitude toward Korea's Hyundai brand after seeing its advertising. This study also compares impacts of behavioral intentions between consumers who recalled and those who could not recall the advertising during the World Cup.

Hypothesis 6: As consumers' feel a more positive attitude toward a brand's "made in ," their behavioral intentions will increase positively.

\section{METHODOLOGY}

A three-part questionnaire was developed in this study. First, the survey asked attitudes toward the brand, attitudes toward the image on products, which are originated from, and an individual's belief on product attributes before and after exposed by advertising during the international event. The survey was pre-tested to about one hundred individual potential consumers in Japan. Subjects were randomly chosen in two cities in Japan - Tokyo and Osaka. For the main survey, approximately four hundred subjects were randomly selected from a telephone directory "Hello Page Japan" based in cities, Tokyo and Osaka, in Japan. Subjects responded both six months before and after the international event. Survey was distributed six month after the international event to avoid the bias from the impact right after the event.

Likert scales, Semantic differential scales, and open-ended questions were used to measure the items. For Likert scale questions, a five-point scale had its extremes labeled "Strongly Disagree" and "Strongly Agree." The questionnaire was developed in English, but translated to Japanese. As proposed by Toy (1982), attitudes toward the brand were measured by averaging the scores on three five-point evaluative scales. Three scales numbered from 1 to 5 (i.e., "poor quality," "high quality," "dislike very much," "like very much," "good," and "bad"). Another five-point scale was used to measure behavioral intention. This study indirectly asks consumers' willingness to make a purchase. Back translation was used to check whether the questionnaire items had been properly translated to Japanese. Quantitative methods were used to analyze this study. Multivariate data analysis, such as positioning analysis was used to find out Japanese consumers' image of the country of origin of the automobiles, while analysis of variance and regression analysis were used to measure Japanese consumers' attitudes toward a specific brand, the Hyundai automobile.

As a situational constraint, the study measures the effects of advertising, exposure during an international event, World Cup 2002 co-hosted by Korea and Japan. The World Cup was chosen since it is known as a great international marketing opportunity (Anonymous 2002). Hyundai, as a sponsored company for this international event was selected in this analysis. In order to measure the major source of advertising for Hyundai during the event, the study asked subjects to rank in order of recognition advertisements among the media, such as TV commercials, print ads, Radio ads, Internet ads, and magazine ads. The sum of the beliefs on attributes of the product and the sum of the image strength for the attributes on the product, made in a specific country are considered as vectors from the model. A vector model, developed by Ahtola (1975) and Mitchell and Olson (1977) was used as the measurements of belief strength and attribute evaluations (Gardner 1983). 


\section{FINDINGS}

Only Japanese subjects were selected for this study; other ethnicities were excluded. Of the 381 respondents, $47.1 \%$ were male and $52.9 \%$ were female. About $43.1 \%$ were between the ages $21-30 ; 28.8 \%$ were between the ages $31-40 ; 10.0 \%$ were in the $41-50$ age group; $7.1 \%$ were in the $51-60$ age group; $11.1 \%$ were age of 65 or older and under 21. Approximately $26.9 \%$ reported that their highest educational level was high school graduate, while $25.4 \%$ had an associate degree, $36.6 \%$ were college graduates, and 5.7\% had done graduate work. More than $60 \%$ had an annual average income between $\$ 20,000$ and $\$ 59,999$.

Various studies have found the factors that affect overall attitudes toward automobile brand and the "made in

." For instance, two important factors found by Erickson et al. (1984) are quality factor including price, reliability, durability, and workmanship and economy factors, such as mileage and price. This study ran the confirmatory factor analysis to identify the factors that affect beliefs on product (i.e., automobile) attributes and factors that associate the country's image with the product. Using principal components analysis as the extraction method and varimax rotation methods with Kaiser Normalization, the most relevant data emerged. This analysis showed a distinct reduction of five factors, with Eigen values over 1.00. The five factors appear to be "economy factor," "technology factor," "quality factor," "service factor," and "design factor." Therefore, this study found three more factors - technology, service, and design - in the previous study done in the 1980s. A separate factor analysis was done to group image variables on automobiles originating from a specific country. Five factors, which have Eigen values over 1.00 also grouped as variables, affect the image of automobiles, made in a specific country. These factors also appear to be "economy factor," "technology factor," "quality factor," "service factor," and "design factor." Therefore, the study found consistencies from two factor analyses. Factor analysis results before and after six months showed similar results with five factors.

This study analyzed linear regression analyses and the analyses of variance. Factor scores were used for regression analyses. Three regression analyses were conducted for before and after the international event. Two regression analyses were conducted for the effects after an international event. Advertising exposure was considered as a dummy variable, 1 and 0 . Therefore, the study assigned 1 when subjects said that they were exposed to automobile advertising of a specific brand during the international event, while it assigned 0 , otherwise. Using the data sets for exposed subjects, the study measures the effects of overall attitude changes if subjects are exposed by different media. The regression results are showed in table 1.

Table 1:

The Effects of Predictors on the Attitudes Toward the Brand "Made In" (Before \& After an International Event)

\begin{tabular}{|c|c|c|c|c|}
\hline \multirow[t]{2}{*}{ Variable } & \multicolumn{2}{|c|}{ Standard Coefficient* } & \multicolumn{2}{|c|}{$t$-value (Sig) } \\
\hline & $\begin{array}{c}\text { Before the } \\
\text { Event }\end{array}$ & $\begin{array}{c}\text { After the } \\
\text { Event }\end{array}$ & $\begin{array}{c}\text { Before the } \\
\text { Event }\end{array}$ & $\begin{array}{c}\text { After the } \\
\text { Event }\end{array}$ \\
\hline Economy Factor of Product Beliefs & .177 & - & $2.896 * *$ & - \\
\hline Performance Factor of Product Beliefs & .342 & .240 & $5.020 * *$ & $2.809 * *$ \\
\hline Performance Factor of Country Image along with Product & .202 & - & $2.949 * *$ & - \\
\hline Design Factors of Country Image along with Product & .169 & .162 & $2.455 * *$ & $2.429 * *$ \\
\hline Service Factor of Product Beliefs & - & .173 & - & $2.745^{* *}$ \\
\hline Design Factor of Product Beliefs & - & .180 & & $2.194 * *$ \\
\hline Technology Factor of Country Image along with Product & - & .307 & - & $4.653 * *$ \\
\hline
\end{tabular}

** Significant at 0.01 level (2-tailed).

Table 1 shows the results of regression analyses for the effects, before and after an international event. First, regression analysis before an international event, was conducted using 10 indicators, including five selected predictors for beliefs on the automobile brand, such as "economy factor," "technology factor," "quality factor," "service factor," and "design factor" and five predictors for the image of the automobile's product, "made in __."Stepwise regression analysis was applied to find how indicators affect overall attitudes toward brands. The results in table 1 
show that four indicators - such as economy and performance factors of an automobile brand, Hyundai, and performance and design factors of an automobile made in a specific country, The Republic of Korea are considered major indicators to predict overall attitudes toward the brand "before" the event $(F=16.242$, significant at .01 level, two-tailed, $r$-square $=.404)$. Another regression analysis was performed to see the effects "after" the international event. The results of stepwise regression analysis in table 1 show that indicators such as performance, service, and design factors of an automobile brand, and technology and design factors of an automobile's country of origin, affect the overall attitude toward the brand $(F=12.879$, significant at .01 level, two-tailed, $r$-square $=.326)$. Another regression analysis was conducted to see how attitudes changed after an international event. Therefore, 12 indicators were used in this regression analysis. Indicators include five selected predictors for belief on the automobile brand, such as "economy factor," "technology factor," "quality factor,", "service factor," and "design factor" as well as five predictors for the automobile's image "made in __," advertising exposure, and advertising strength. Therefore, hypothesis 1 and 2 were accepted.

Table 2 shows the results of regression analysis when advertising exposure was used as a dummy variable $(F$ $=14.565$, significant at .01 level, two-tailed, $r$-square $=.371)$. As table 2 shows, this study found that the impact of the indicators on attitudes toward brands changes when subjects are exposed to advertising during an international event. Therefore, hypothesis 3 was accepted. Hypothesis 4 was also accepted because the result shows that a higher degree of recall on advertising significantly affects the overall attitudes toward a brand.

Table 2:

The Advertising Effects on the Attitudes Toward the Brand "Made In"

\begin{tabular}{|l|c|c|}
\hline Variable & Standard Coefficient & $\boldsymbol{t}^{*}$-value (Sig) \\
\hline Performance Factor of Product Beliefs & .321 & $3.909^{* *}$ \\
\hline Service Factor of Product Beliefs & .219 & $3.144^{* *}$ \\
\hline Design Factor of Product Beliefs & .241 & $3.213^{* *}$ \\
\hline Recall on Advertising & .239 & $3.101^{* *}$ \\
\hline Strength of Recall on Advertising & .342 & $4.133^{* *}$ \\
\hline Technology Factor of Country Image along with Product & .411 & $6.411^{* *}$ \\
\hline Design Factors of Country Image along with Product & .217 & $3.321^{* *}$ \\
\hline
\end{tabular}

** Significant at 0.01 level (2-tailed).

The impact of advertising exposure on overall attitudes toward a brand based on different media was hypothesized (H5: see table 3). This study found that about $76 \%$ of subjects recognized advertising from TV commercials and signboards during the game; 13\% recognized advertising from newspaper ads; $5 \%$ from magazine ads, 3\% from Internet ads, $2 \%$ radio ads, and the remaining 1\% was other. Strength of advertising recall on overall attitudes toward the brand was higher when subjects were exposed to TV commercials and signboards than to other media. Therefore, hypothesis 5 was accepted.

Table 3:

The Effects of Advertising Recall by Different Media

\begin{tabular}{|l|c|c|}
\hline Media & Standard Coefficient* & $\boldsymbol{t}$-value (Sig) \\
\hline TV (Commercials and Signboard) & .417 & $5.119^{* *}$ \\
\hline Newspaper ads & .210 & $3.011^{* *}$ \\
\hline Radio Ads & .171 & $1.853^{* *}$ \\
\hline Internet Ads & .165 & $1.644^{* *}$ \\
\hline Magazine ads & .151 & $1.905^{* *}$ \\
\hline \multicolumn{2}{|l}{} \\
\hline
\end{tabular}

As hypothesized (H6), consumers' behavioral intentions were increased as they have more positive attitude toward a brand's "made in ." This study also found that this impact was higher with consumers who recalled 
advertising ( $t$-value: 5.617, significant at 0.05 level) than with consumers who did not recall the advertising ( $t$-value: 3.191 , significant at 0.05 level).

\section{DISCUSSION AND CONCLUSION}

In this paper, authors measure how consumers' attitudes toward brands change after an international event. The effects of advertising during an international event have been considered because advertising exposure during such events could have a dual impact addressing beliefs on both the brand and the country at once. The impact of marketing campaigns during the World Cup has been measured in this study while many researches have addressed this issue. To measure effects, this study considers the impact of different degrees of recall regarding how advertising during an international event affects consumers' attitudes toward brands, as well as how advertising by different media affects attitudes toward brands.

This study found that consumers' attitudes have changed during the international event. Although consumers could not recall specific brand after an international event, attitudes toward the brand have increased positively, while recalled consumers' attitudes toward the brand have changed much positively. This study also found factors affect consumers' beliefs about the brands and attributes of automobiles and also the country's image. The factors that affect beliefs about product attributes, country image, and the brand's "made in __ are the "economy factor," "technology factor," "quality factor," "service factor," and "design factor." Compared to the previous study done in the 1980s, which found the factors for beliefs and attitudes on automobiles, this study found other factors, such as the technology factor, service factor, and design factor. The results also provided evidence of advertising's effects during an international event on attitudes toward brands. The country of origin along with the brand, beliefs about a product's attributes, and attitudes toward advertising all affected overall attitudes toward a brand, originating from a specific country. The results of this study indicated that the aforementioned factors affect attitude changes toward a brand and its country of origin.

When consumers recalled advertising during an international event and when the strength of that recall was higher, their attitude toward a brand's "made in __ "was more favorable. Another important finding of this study is that potential consumers' attitudes and behavioral intentions toward a brand made in the host country increase positively for consumers who recall the advertising. That impact also increased for consumers who do not recall the advertising. Therefore, the result implied that an international event itself significantly improves both the host country's image and the image of all brands made in that country while consumers cannot recall the specific advertising. Similarly, the impact of attitudes toward a brand on behavioral intentions also increased significantly even though consumers could not recall the advertising. Behavioral intentions positively increase after an international event even though consumers did not recall the specific advertising. Therefore, this study conclude from the result that the international event positively affects attitudes and behavioral intentions toward brands, made in the host country not just because of the advertising, but because consumers perceive a positive image about the brand and the country together through many other campaigns.

This study contributed to theory and model development. While many researches applied Fishbein model to estimate variables' relationships, this study extended the model considering many effects, such as consumers' beliefs on country image along with product attributes, and the attitudes toward brands labeled "made in," and product attributes after an international event (i.e., World Cup), which was hardly measured by researchers. The modified Fishbein model proposed in this study is extended from two previous studies, Mitchell and Olson (1981) and Erickson, Johanson, and Chao (1984) by considering both impacts of an international event and country image.

The study has some limitations. Although the study measures attitude changes six months after an international event, this is a short period to build brand equity toward a brand. Previous studies have suggested that there might be enough time to change brand attitudes, build brand awareness, or change brand image. Therefore, further research should measure attitude changes after a longer period of advertising exposure. Future study should measure actual behavior, which is the last stage from the Fishbein model after the behavioral intentions. This study used subjects only from two major cities in Japan; thus further research should select subjects from various regions in Japan. Future research should also consider the different degree of involvement for an individual's source of 
advertising. Another limitation of this study is impact of co-hosting country's impact. How does the advertising by hosting country differ from by non-hosting country should be included in our future research.

Major findings suggest that in Japan brand images of automobiles are significantly associated with the country and make. A special event affects consumers' attitudes toward brands as it increases brand image along with country image, but the impact does not have a significant effect in a short period of time. Further, the study also provides suggestions to manufacturers in order to succeed in global markets.

\section{REFERENCES}

1. Anderson, W. T. and Cunningham, William H. (1972), Gauging Foreign Product Promotion, Journal of Advertising Research, February, 29-34.

2. Ajzen, Icek and Fishbein, Martin (1980), Understanding Attitudes and Predicting Social Behavior, Englewood Cliffs, NJ, Prentice-Hall.

3. Ahtola, Olli T. (1975), The Vector Model of Preferences: An Alternative to the Fishbein Model, Journal of Marketing Research, 12 (February), 52-59.

4. $\quad$ Anonymous (2002), Soccer Fits the Bill,” Marketing news, February.

5. Bilkey, Warren J. and Erik Nes (1982), Country-of-Origin Effects on Product Evaluations, Journal of International Business Studies, 1 (Spring/Summer), 89-99.

6. $\quad$ Erickson, Gary M., Johansson, Johny K., and Chao, Paul (1984), Image Variables in Multi-Attribute Product Evaluations: Country-of-Origin Effects, Journal of Consumer Research, 11 (September), 694-99.

7. Fishbein, Martin and Icek Ajzen (1975), Belief, Attitude, Intention and Behavior: An Introduction to Theory and Research, Reading, MA: Addison-Wesley.

8. Gardner, Meryl Paula (1983), Advertising Effects on Attributes Recalled and Criteria Used for Brand Evaluations, Journal of Consumer Research, 10 (December), 310-18.

9. Han, C. Min (1989), Country Image: Halo or Summary Construct? Journal of Marketing Research, 26 (May), 222-229.

10. Haskins, J. B. (1964), Factual Recall as a Measure of Advertising Effectiveness, Journal of Advertising Research, 4 (March), 2-8.

11. Hansen, Robert A. and Scott, Carol A. (1976), Comments on Attribution Theory and Advertiser Credibility, Journal of Marketing Research, 13, May, 193-197.

12. Hoffman, Donna L., Novak, Thomas, P., and Chatterjee, Patrali (1995), Commercial Scenarios for the Web: Opportunities and Challenges, The Journal of Computer-Mediated Communication, Special Issue on Electronic Commerce, 1(3).

13. Hofstede, Geert (1991), Cultures and Organizations: Software of the Mind, London, McGraw-Hill.

14. Holbrook, Morris B. (1978), Beyond Attitude Structure: Toward the Informational Determinants of Attitude, Journal of Marketing Research, 15, November, 545-556.

15. Johansson, Johny K., Douglas Susan P., and Nonaka, Ikujiro (1985), Assessing the Impact of Country of Origin on Product Evaluations: A New Methodological Perspective, Journal of Marketing Research, 22, November, 388-96.

16. Kaynak, Erdener. and Kuchkemiroglu, Orsay, and Hyder, Akmal S. (2000), Consumers' Country-of-Origin (COO) perceptions of imported products in a homogenous less-developed country, European Journal of Marketing, 34(9/10), 1221-1241.

17. Kelley, H. H. (1971), Attribution in Social Interaction, in Edward E. Jones, et al., eds. Attribution Perceiving the Causes of Behavior, Morristown, New Jersey, General Learning Press, 1-26.

18. Krugman, H. E. (1972), Brain Wave Measures of Media Involvement, Journal of Advertising Research, 11 (February), 3-10.

19. Leclerc, France and Schmitt, Bernd H. (1994), Foreign Branding and Its Effects on Product Perceptions and Attitudes, Journal of Marketing Research, 31(2), 263-271.

20. Lots, Sherry L. and Hu, Michael Y. (2001), Diluting Negative Country of Origin Stereotypes: A Social Stereotype Approach, Journal of Marketing Management, 17, 105-135.

21. Mitchell, Andrew A. and Olson, Jerry C. (1981), Are Product Attribute Beliefs the Only Mediator of Advertising Effects on Brand Attitude? Journal of Marketing Research, 18 (August), 318-32. 
22. Papadopoulos, Nicolas (1993), What Product and Country Images Are and Are Not, In: Product-Country Images: Impact and Role in International marketing (Eds.) Papadopoulos, Nicholas and Heslop, Louise A. (New York), International Business Press.

23. Rayport and Jaworski (2001), Cases in E-Commerce, McGraw-Hill.

24. Runyon, Kenneth E. and Stewart, David W. (1987), Consumer Behavior, Third edition, Merrill Publishing Company.

25. Samiee, Saeed (1994), Customer Evaluation of Products in a Global Market, Journal of International Business Studies, 25(3), 579-604.

26. Settle, Robert B. and Gorden, Linda I. (1976), Attribution Theory and Advertiser Credibility, Journal of Marketing Research, 11, May, 181-185.

27. Singh, Surendra N. and Rothschild, Michael L. (1983), Recognition as a Measure of Learning from Television Commercials, Journal of Marketing Research, 20 (August), 235-48.

28. Toy, Daniel R. (1982), Monitoring Communication Effects: A Cognitive Structure/Cognitive Response Approach, Journal of Consumer Research, 9 (June), 66-76.

29. Wilkie, William L. and Edgar A. Pessemier (1973), Issues in Marketing's Use of Multi-Attribute Attitude Models, Journal of Marketing Research, 10 (November), 428-41.

30. Wright, Peter (1974), Analyzing Media Effects on Advertising Response, Public Opinion Quarterly, 38, 192205.

31. Wright, Peter (1978), Extracting Information from Mass Media Advertisements, in The Effect of Information on Consumer and Market Behavior, ed. Andrew Mitchell, Chicago: American Marketing Association, 61-64. 


\section{NOTES}

